\title{
Co-infection, super-infection and viral interference in HIV
}

\author{
Azaria Remion $^{1^{*}}$, Marc Delord ${ }^{2}$, Sentob Saragosti ${ }^{1}$, Fabrizio Mammano ${ }^{1}$ \\ From Frontiers of Retrovirology: Complex retroviruses, retroelements and their hosts \\ Cambridge, UK. 16-18 September 2013
}

\section{Background}

Viral interference is a phenomenon by which a virusinfected cell displays reduced susceptibility to re-infection. This phenomenon, also called superinfection resistance, is generally due to occupation or down-modulation of cellular receptors. In this respect, the principal mechanism of HIV superinfection resistance is down-modulation of the $\mathrm{CD} 4$ receptor from the cell surface mediated by Env, Vpu and Nef. Recent data, however, strongly suggest that HIV superinfection resistance also involves CD4-independent mechanisms that remain to be fully understood. Our aim was to explore the dynamics and mechanisms of CD4independent viral interference in HIV.

\section{Material and methods}

To quantify the infection by the first and the super-infecting virus, we used two isogenic HIV proviral clones, differing only in the expression of a marker protein (GFP and HSA). To analyze the dynamics of viral interference, the superinfecting virus was added at different times after the initial virus $(0,3,6,12,18$ and $24 \mathrm{~h})$. We prevented virus spread in culture by using single cycle virus infection. The number of cells expressing none, one, or both reporter proteins were measured by FACS analysis, and used to determine whether double infection occurred at frequencies expected for independent infection events.

\section{Results}

In the case of co-infection (two viruses added at the same time), the frequency of double infected cells was significantly higher than it would be expected if the two infection events were independent. This result is consistent with previous literature [1].

By delaying the infection of the second virus (superinfection) and comparing the frequency of double infected

${ }^{1}$ INSERM U941, Université Paris Diderot, Paris, France

Full list of author information is available at the end of the article cells to those observed for co-infection, we show evidence of viral interference starting $6 \mathrm{~h}$ post-initial infection, which gained statistical significance when the second infection was performed $18 \mathrm{~h}$ and $24 \mathrm{~h}$ after the first one. Using a virus pseudotyped by the amphotropic-MLV Env for the second infection, we measured a similar level of interference up to $18 \mathrm{~h}$ post-initial infection. This result strongly suggests that, for these early time points, virus interference is a CD4-independent phenomenon.

\section{Conclusions}

Our experimental system allowed us to explore the efficiency of coinfection and the kinetics of viral interference in HIV. We confirmed that co-infection leads to a higher frequency of double infected cells than would be expected for independent infection events. In the setting of superinfection, only a few hours are required for the induction of measurable viral interference. This rapid phenomenon is largely independent of CD4-expression. Our experimental system will allow the exploration of the viral genes and the cellular mechanisms responsible for the early establishment of HIV interference.

\section{Acknowledgments}

This work was supported in part by Conseil Régional Martinique.

\section{Authors' details \\ ${ }^{1}$ INSERM U941, Université Paris Diderot, Paris, France. ${ }^{2}$ Hôpital Saint-Louis,} Paris, France.

Published: 19 September 2013

Reference

1. Dang, et al: Nonrandom HIV-1 infection and double infection via direct and cell-mediated pathways. Proc Natl Acad Sci U S A 2004, 101:632-637.

doi:10.1186/1742-4690-10-S1-P72

Cite this article as: Remion et al:: Co-infection, super-infection and viral interference in HIV. Retrovirology 2013 10(Suppl 1):P72.
C 2013 Remion et al; licensee BioMed Central Ltd. This is an Open Access article distributed under the terms of the Creative Commons Attribution License (http://creativecommons.org/licenses/by/2.0), which permits unrestricted use, distribution, and reproduction in any medium, provided the original work is properly cited. 